\title{
A Comparative Study of Thematic Progression Patterns Between Narration and Argumentation in New Concept English
}

\author{
Xiaoli Guo ${ }^{1, *}$ \\ ${ }^{1}$ College of Foreign Languages and Cultures, Xiamen University, Xiamen, Fujian, China \\ *Xiaoli Guo. Email: z2543550350@foxmail.com
}

\begin{abstract}
Thematic progression is an important concept in systemic functional linguistics. Apart from its theoretical value, it means a lot to reading comprehension and essay-writing because thematic progression patterns reveal how sentences are connected. Most studies are based on one specific text type rather than comparing different text types. This paper, based on narrative texts and argumentative ones, compares the similarities and differences in the distribution of thematic progression patterns in two different text types and finds that both types employ various thematic progression patterns, and thematic progression with a constant theme is the most common pattern. Furthermore, thematic progression patterns are more evenly distributed in argumentative samples than in narrative ones. The second difference lies in themes exploited in two types.
\end{abstract}

Keywords: thematic progression, narration, argumentation, New Concept English

\section{INTRODUCTION}

The concepts Theme and Rheme are proposed by an influential scholar of Prague School, V. Mathesius to explore the roles of different constituents in a sentence. In Mathesius' view, theme is the element situated at the beginning of a sentence, functioning to introduce the topic, while rheme is the rest of a sentence. When a sentence stands on its own, its theme and rheme are isolated. However, in real life, nearly all the texts include two or more sentences and paragraphs. Themes and rhemes between sentences are connected in one way or another. The connections are called theme progression (TP). Based on the previous studies, Danes [1] proposed three types of TP patterns. Other scholars later explore possible TP patterns [2-4]. They all agree the TP contributes a lot to the cohesion of texts, thus contributing to understanding the discourse. $\mathrm{Hu}$ [5] states that the correlation between themes and rhemes is an important means to achieve textual cohesion. What's more, the choice of theme and TP pattern is not unvaried in different types of texts. When readers grasp the tendency, it must be easier for them to connect the sentences, thus comprehending the text further and even facilitating their writing of different text types.
In China, since the publication in 1997 of the revised New Concept English, this series of textbooks, consisting of four books, has gone viral. Thousands of teachers in elementary and middle schools, even in universities, recommend this textbook to their students. There is no doubt that New Concept English has exerted a profound impact on Chinese English learners. Thus, several samples are selected from this textbook.

At present, studies on applying TP to text analysis or text comprehension are largely on one specific text type [6-7], lacking comparative research. As articles in this textbook are mainly narrative ones, plus some argumentative essays, this study compares TP patterns in those two kinds of essays. Ten essays, five narratives, and five argumentative ones are randomly selected from Book 3 [8] and Book 4 [9] because they are for more advanced learners.

\section{LITERATURE REVIEW}

A number of scholars have explored the relationship between TP patterns and different text types [10-13]. Meanwhile, some scholars focus on narrations and argumentations. For example, Cheng [6] studied TP patterns in argumentative texts. Her study suggested that nominal groups are the most frequently used theme, 
prepositional phrases ranking second. Lin [7], based on 20 narrative articles in New Concept English (Book 2), found that TP with a constant theme is the most frequent pattern, and the second is simple linear TP, with TP with a constant rheme as the least used one. Wang [14] found cohesion between sentences in narrative discourse is usually accomplished by TP with a constant theme and simple linear TP.

However, only a few studies are comparative ones. Bian [15] compared TP patterns between narrations and argumentations. However, the reading materials Bian selected are from famous writings, indicating that English learners are not quite familiar with them, thus exerting little influence on their process of English learning.

To summarize, scholars both at home and abroad explore TP patterns in text analysis, but most of them analyze one type of text; only a few scholars focus on comparative studies. Therefore, based on articles selected from a quite popular textbook among English learners, this paper compared themes and TP patterns in narrative and argumentative texts.

\section{THEORETICAL BASIS}

\subsection{Theme and Rheme}

The concepts theme and rheme are first proposed by $\mathrm{V}$. Mathesius to deal with the role of different elements in the sentence. He points out that the elements at the beginning of sentences are the point of departure, i.e., the theme, and the rest of the sentence is rheme. Theme generally indicates given information while rheme, new information.

Later, M.A.K. Halliday develops the concept theme. Halliday [16:37] states that the theme is "the element which serves as the point of departure of the message." The remainder of the message is called the rheme. He also classifies theme into simple theme, multiple theme, and clausal theme. The simple theme refers to a single element within the clause. It is an independent constituent and cannot be divided into smaller functional units, usually composed of a noun phrase, adverb phrase, or prepositional phrase. For example,

(a) With sobs and tears (T), he sorted out those of the 1argest size(R).

(b) Slowly and quietly (T) he pushed the door open(R).

The underlined parts of both sentence (a) and sentence (b) serve as the simple theme. In sentence (b), though there are two words, Slowly and quietly cannot be divided into smaller functional units. Thus, it is an independent phrase describing the way of pushing. The multiple theme is composed of multiple functional components and usually contains two or more phrases, embodying different semantic functions of the theme. It is classified into the topical theme, interpersonal theme, and textual theme, corresponding to ideational, interpersonal, and textual metafunctions.

(c) Conversely, possibly, females(T) felt more at ease responding to a non-specific female address( $R$ ).

In this sentence, conversely, possibly, and females are textual, interpersonal, and topical themes, respectively. As for the clausal theme, it refers to a clause as the theme. Meanwhile, the clause acting as the theme can be further divided into theme and rheme.

(d) If winter comes $(\mathrm{T})$, can spring be far behind(R)?

(e) She married $(\mathrm{T})$ and became pregnant $(\mathrm{R})$.

(f) Give it away (T) if you don't like that pen(R).

(g) If winter $(\mathrm{T})$ comes $(\mathrm{R})$, can spring $(\mathrm{T})$ be far behind $(\mathrm{R})$ ?

\subsection{Thematic Progression Pattern}

Each clause has its own theme and rheme. When the clause exists alone, the theme and rheme do not change. In real life, however, most text is composed of two or more clauses. Theme changes and connects with other themes and rhemes. These connections and changes are called thematic progression (TP).

This concept was first proposed by Denis [1]. Based on analysis of Czech texts and other language materials, he ascertained three main types of TP: simple linear TP, TP with a continuous (constant) theme, and TP with derived themes, as shown by the following three figures.

$$
\begin{aligned}
\mathrm{T}_{1} \rightarrow \mathrm{R}_{1} & \\
& \\
& \\
\mathrm{~T}_{2}\left(=\mathrm{R}_{1}\right) \rightarrow & \mathrm{R}_{2} \\
& \downarrow \\
& \mathrm{T}_{3}\left(=\mathrm{R}_{2}\right) \rightarrow \mathrm{R}_{3}
\end{aligned}
$$

Figure 1. simple linear TP

$$
\begin{aligned}
& \mathrm{T}_{1} \longrightarrow \mathrm{R}_{1} \\
& \downarrow \\
& \mathrm{T}_{1} \longrightarrow \mathrm{R}_{2} \\
& \downarrow \\
& \mathrm{T}_{1} \longrightarrow \mathrm{R}_{3}
\end{aligned}
$$

Figure 2. TP with a continuous (constant) theme

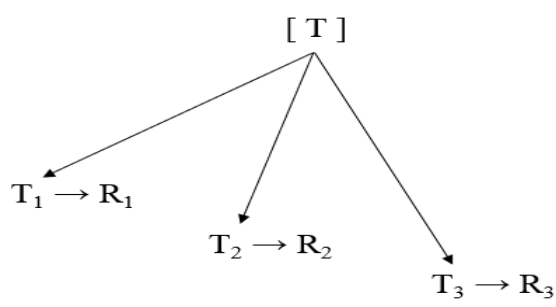

Figure 3. TP with derived themes 
After Denis, many scholars try to present a comprehensive classification of TP patterns [2,4]. Summarizing previous studies, Zhu [17] proposed four common types of TP-TP with a constant theme, TP with a constant rheme, simple linear TP, and TP with derived Themes. As this division fully reveals the semantic relationship between sentences and these four patterns of TP are present in various languages, and text types, Zhu's classification of TP patterns is adopted.

\section{RESULTS AND DISCUSSION}

Five narrative articles randomly selected from Book 3 are It's only me, Daniel Mendoza, Five pounds too dear, The silent village, and A spot of bother; while five argumentative ones from Book 4 are Youth, The sporting spirit, How to grow old, Knowledge and progress, and Beauty. The distributions of TP patterns in selected narrative and argumentative texts are listed in table 1 and table 2 .

Table 1. The Distribution of TP Patterns in Narrative Texts

\begin{tabular}{|c|c|c|c|c|c|}
\hline sample text & $\begin{array}{c}\text { TP with a constant } \\
\text { Theme }\end{array}$ & $\begin{array}{c}\text { TP with a constant } \\
\text { Rheme }\end{array}$ & $\begin{array}{c}\text { Simple Linear } \\
\text { TP }\end{array}$ & $\begin{array}{c}\text { TP with Derived } \\
\text { Themes }\end{array}$ & Total \\
\hline 1 & 16 & 0 & 3 & 0 & 19 \\
\hline 2 & 21 & 1 & 5 & 0 & 27 \\
\hline 3 & 17 & 1 & 6 & 1 & 25 \\
\hline 4 & 19 & 1 & 5 & 0 & 25 \\
\hline 5 & 18 & 0 & 22 & 1 & 21 \\
\hline Total & 91 & 3 & $18.80 \%$ & $0.85 \%$ & 117 \\
\hline Percentage & $77.78 \%$ & $2.56 \%$ & & & $100 \%$ \\
\hline
\end{tabular}

This table shows the number and percentage of each TP pattern. TP with a constant theme is the most frequently used pattern in narrative samples, accounting for $77.78 \%$, followed by simple linear TP (18.80\%), TP with a constant rheme $(2.56 \%)$, and $\mathrm{TP}$ with derived themes, which is only $0.85 \%$.

Table 2. The Distribution of TP Patterns in Argumentative Samples

\begin{tabular}{|c|c|c|c|c|c|}
\hline sample text & $\begin{array}{c}\text { TP with a constant } \\
\text { Theme }\end{array}$ & $\begin{array}{c}\text { TP with a constant } \\
\text { Rheme }\end{array}$ & $\begin{array}{c}\text { Simple Linear } \\
\text { TP }\end{array}$ & TP with Derived Themes & Total \\
\hline 1 & 13 & 2 & 3 & 0 & 18 \\
\hline 2 & 10 & 0 & 4 & 0 & 14 \\
\hline 3 & 9 & 3 & 2 & 0 & 14 \\
\hline 4 & 11 & 3 & 8 & 3 & 21 \\
\hline 5 & 10 & 1 & 21 & 3 & 22 \\
\hline Total & 53 & 9 & $23.60 \%$ & $6.74 \%$ & $100 \%$ \\
\hline Percentage & $59.55 \%$ & $10.11 \%$ & & & 89 \\
\hline
\end{tabular}

On the other hand, table 2 shows the distribution of TP patterns in argumentative texts. Similar to that in narrative texts, TP with a constant theme is far more commonly used in argumentations, which accounts for $59.55 \%$. Simple linear TP ranks second with a percentage of $23.60 \%$. Then it is followed by TP with a constant rheme $(10.11 \%)$ and TP with derived themes $(6.74 \%)$.

\subsection{Similarities in TP Patterns in Both Types}

From the above tables, some similarities are identified. Firstly, the order of four TP patterns is the same --TP with a constant theme, simple linear TP, TP with a constant rheme, and TP with derived themes. TP with a constant theme is the most frequently used because, in narrations, writers aim to narrate what happens to the main character. Therefore, the protagonist is usually set as the subject of a sentence, while in argumentations, there is a topic. What the author discusses is to illustrate it. Thus, the topic often functions as a subject.
Secondly, the use of different TP patterns in two types of texts is not the same. In other words, the distribution is not balanced in each text. Although the choice of TP patterns is restricted by the text type, there are no rules specifying TP patterns in a text. Writing itself is a random creation to a certain degree. Writers combine more than one TP pattern to make the text flexible.

\subsection{Differences in TP Patterns in Both Types}

In addition to similarities, there are significant differences between the two text types. Despite unbalanced distribution in both types, distribution in argumentative samples is more balanced than that in narrative samples. In narrations, the major TP pattern accounts for $77.78 \%$ while the minor pattern, only $0.85 \%$. In contrast, four TP patterns in argumentations are more evenly distributed, with $59.55 \%$ and $6.74 \%$ as the highest and lowest ones, respectively. This is because, in argumentations, writers discuss or introduce various aspects to persuade readers. For instance, in sample 3, 
How to grow old, the author tries to persuade people that there is no need for the old to fear death. To introduce his viewpoint, the author first justifies this feeling in young people and then believes that it is "abject and ignoble" for an old man to fear death. Next, the author offers a way to overcome the fear and finally illustrates his idea with a metaphor. This is a logical discourse, and every section has its own subtopic and occasionally connects with each other. Thus, TP with a constant theme is not used all time, but with the other two TP patterns.

Secondly, themes used in narrative articles and argumentative articles also differ a lot. Themes in the former texts are more concentrated and unvaried than those in the latter samples. For instance, the narrative sample It's only me and the argumentative sample The sporting spirit are compared in terms of their themes. In It's only me, it narrates what occurred to Mrs. Richards. Hence, most themes are the phrase Mrs. Richards or the personal pronoun she; while in The sporting spirit, the themes vary a lot, but they all serve to discuss the topic. Personal pronouns manifest themselves, too. However, rather than referring to a particular person, they make general references like you, one, anyone, an individual, to emphasize the arguments rather than the person.

\section{CONCLUSION}

Thematic progression pattern, contributing to text cohesion, plays a critical part in reading comprehension and essay-writing. Countless scholars devote themselves to studies on text analysis and demonstrate the significance and application. Existing studies focus on one specific text type, such as scientific texts, speeches, and advertisements. Only a few studies are comparative ones. However, their materials are selected from literary works, indicating they are not written for learners. Therefore, text samples are selected from a textbook designed for English learners to compare the similarities and differences in the distribution of TP patterns between two types of texts - narrative and argumentative texts. Realizing TP patterns, learners are sure to grasp the main idea more easily and, meanwhile, are more likely to write logical and well-organized articles. By analysing the texts, this paper finds that both types employ various TP patterns, and TP with a constant theme is the most common pattern. In the meantime, TP patterns are more evenly distributed in argumentative samples than in narrative one. Besides, themes in narrations tend to refer to the protagonist, while themes in argumentations do not have such a tendency and are usually more diverse to demonstrate the topic from different facets. Despite the findings, this paper needs improvement. For instance, more samples are needed to make the conclusion more pervasive and more universal.

\section{REFERENCES}

[1] Danes, F. (1974). Functional sentence perspective and the organization of the text. Papers on functional sentence perspective, 23, 106-128.

[2] Xu, S.H. (1982). Theme and Rheme. Foreign Language Teaching and Research, (01), 1-9.

[3] Huang, Y. (1985). On English Theme Rheme. Journal of Foreign Languages, (05), 34-38+20.

[4] Huang, G.W. (1988). Essentials of Text Analysis. Changsha: Hunan Education Publishing House.

[5] Hu, Z.L. (1994). Discourse cohesion and coherence. Shanghai: Shanghai Foreign Language Education Press.

[6] Cheng, A. Q. (2011). Study on the Explanatory Power of Theme-rheme Theory to Argumentation. Journal of Xihua University (Philosophy \& Social Science), 30(04), 79-84.

[7] Lin, T. (2012). A Study of The Thematic Structure of English Texts—-from the perspective of narrative texts. Journal of Henan University of Technology (Social Science Edition), 8(01), 82-84.

[8] Alexander, L.G. \& He, Q. X. 1997. New Concept English (Book 3). Foreign Language Teaching and Research Press.

[9] Alexander, L.G. \& He, Q. X. 1997. New Concept English (Book 4). Foreign Language Teaching and Research Press.

[10] Nwogu, K. \& Bloor, T. (2011). Thematic progression in professional and popular medical texts. Berlin: Mouton de Gruyter.

[11] Ghadessy, M. (Ed.). (1995). Thematic Development of English Texts. A\&C Black.

[12] Guo, Q. (2013). Thematic progression and discourse genre: A Case Study of Obama's Inaugural Speech. Journal of Jishou University (Social Sciences), 34(S1), 103-105.

[13] Liu, L., \& Tucker, G. (2015). Thematic choice and progression in English and Chinese radio news texts: a systemic functional analysis. Text \& Talk, 35(4), 481-504.

[14] Wang, Z.K. (2016). The Cohesion of Theme-Rheme Progression pattern in Narrative Discourse. Journal of Jiaozuo University, 30(02), 16-18+28.

[15] Bian, Y.Y. (2016). A Comparative Study of Thematic Progression Patterns between English Argumentation and English Narration (Master's thesis, Northeast Forestry University) 
[16] Halliday, M. A. K. (1994). An introduction to functional grammar. Beijing: Foreign Language Teaching and Research Press.

[17] Zhu, Y.S. (1995). Patterns of Thematic Progression and Text Analysis. Foreign Language Teaching and Research, (03), 6-12+80. 